\title{
Investigator experiences with financial conflicts of interest in clinical trials
}

\author{
Paula A Rochon ${ }^{1 *}$, Melanie Sekeres², John Hoey ${ }^{3}$, Joel Lexchin ${ }^{4,5,6}$, Lorraine E Ferris ${ }^{3}$, David Moher ${ }^{7}$, Wei Wu' \\ Sunila R Kalkar ${ }^{1}$, Marleen Van Laethem ${ }^{8,9}$, Andrea Gruneir ${ }^{1}$, Jennifer Gold ${ }^{10}$, James Maskalyk ${ }^{11}$, David L Streiner ${ }^{12}$, \\ Nathan Taback ${ }^{3}$ An-Wen Chan ${ }^{1}$
}

\begin{abstract}
Background: Financial conflicts of interest (fCOI) can introduce actions that bias clinical trial results and reduce their objectivity. We obtained information from investigators about adherence to practices that minimize the introduction of such bias in their clinical trials experience.

Methods: Email survey of clinical trial investigators from Canadian sites to learn about adherence to practices that help maintain research independence across all stages of trial preparation, conduct, and dissemination. The main outcome was the proportion of investigators that reported full adherence to preferred trial practices for all of their trials conducted from 2001-2006, stratified by funding source.

Results: 844 investigators responded (76\%) and 732 (66\%) provided useful information. Full adherence to preferred clinical trial practices was highest for institutional review of signed contracts and budgets $(82 \%$ and $75 \%$ of investigators respectively). Lower rates of full adherence were reported for the other two practices in the trial preparation stage (avoidance of confidentiality clauses, 12\%; trial registration after 2005, 39\%). Lower rates of full adherence were reported for 7 practices in the trial conduct (35\% to 43\%) and dissemination (53\% to 64\%) stages, particularly in industry funded trials. 269 investigators personally experienced $(n=85)$ or witnessed $(n=236)$ a fCOl; over $70 \%$ of these situations related to industry trials.
\end{abstract}

Conclusion: Full adherence to practices designed to promote the objectivity of research varied across trial stages and was low overall, particularly for industry funded trials.

\section{Background}

An estimated 20,000 trials are initiated internationally each year [1] with over 500 published each month [2]. Participants volunteer for these trials under the assumption that their efforts will contribute to the advancement of science. Accordingly, study results need to be objective, publicly available, and responsibly applied to advance knowledge and healthcare practice.

Concern about the potential impact of financial conflicts of interest (fCOI) on research conduct has led to recommendations for clinical trial practices designed to maintain an investigator's independence and to avoid the introduction of bias and suppression of results.

\footnotetext{
* Correspondence: paula.rochon@utoronto.ca

'Women's College Research Institute at Women's College Hospital, Toronto, Canada

Full list of author information is available at the end of the article
}

Practices that promote the objectivity of research have been outlined in national standards for research ethics boards [3-6], requirements for federally funded research $[3,7]$ guidance for academic institutions [8,9], requirements for trial registration [10] and for manuscripts submitted to biomedical journals [11-13]. We know little about adherence to these practices in the conduct of clinical trials.

We surveyed investigators about their experiences with practices designed to ensure the objectivity of research across all stages of industry and non-industry funded trials.

\section{Methods \\ Survey Participants and Data Collection}

We identified investigators conducting clinical trials at Canadian sites using the meta-register of Controlled

\section{Biomed Central}


Trials [14] to search for trials registered in International Standard Randomized Controlled Trial Number (ISRCTN) or Clinicaltrials.gov. E-mail addresses were obtained from the trial registry record or, if unavailable, from an internet search of public sources. Our study was approved by the research ethics board at the Baycrest Centre affiliated with the University of Toronto.

We identified 1,127 unique investigators based in Canada with a valid e-mail address. From May through November, 2006, we e-mailed potential respondents, asking them to complete an online questionnaire. A five dollar gift card was offered upon completion. Consent was considered to be implied when the investigators completed the on-line survey. Investigators were told that results will be presented as aggregate data only. Non-responders and those completing only a small portion of the questionnaire were sent up to five reminder e-mails at one-to two-week intervals. After excluding those who were unreachable $(\mathrm{n}=18)$, defined as four auto-generated 'out of office' replies, the final sample was 1,109 .

\section{Survey Design and Content}

Our survey obtained information about an investigator's experience with situations related to fCOI that could introduce bias into a trial. The questionnaire content was based on the International Committee of Medical Journal Editors' (ICMJE) uniform requirements for manuscripts submitted to biomedical journals [11]; the fCOI literature; and the input of our research team (see Additional file 1). The ICMJE statement [11] was expanded in 2008 [12]. These criteria have been widely accepted by organizations including the World Association of Medical Editors (WAME) [15] and Consolidated Standards of Reporting Trials (CONSORT) [16]

Given that trials often take from four to eight years to conduct and publish, we asked investigators to describe their experiences over a five year time frame (20012006). We collected information about situations that could introduce bias during the stages of trial preparation (review of contracts and budgets, confidentiality clauses, trial registration), conduct (trial design, data access and ownership, data analysis and interpretation) and dissemination (manuscript preparation and publication). For each situation we identified what we considered to be preferred practice to protect an investigator's independence and to avoid the introduction of bias. Table 1 lists the preferred practices to promote the objectivity of research and the rationale for their inclusion.

\section{Personal Experiences with $\mathrm{fCOI}$}

We asked investigators if they had ever experienced fCOI or witnessed a situation involving fCOI. If so, they were asked to describe the situation and whether these experiences took place in the context of an industry or non-industry funded trial.

\section{Statistical analysis}

We used descriptive statistics to characterize respondents and their trial experience. Survey data were aggregated anonymously.

Our main study outcome was the percentage of investigators that reported full adherence to each preferred practice in all of their trials conducted from 2001-2006. Free text comments provided by investigators about their own personal or witnessed experiences with fCOI were summarized into thematic areas by two authors (SRK and WW). The initial agreement on the thematic areas was $91 \%$ for investigators' own experiences and $97 \%$ for experiences witnessed in a colleague. All differences were resolved by consensus.

\section{Results}

Of 1,109 eligible investigators at Canadian sites, 844 (76\%) responded. Among responders, 76 (7\%) declined participation and $36(3 \%)$ answered only the preliminary administrative questions. 732 investigators (included response rate, $66 \%$ ) were in our final analysis. Of these, 32 did not provide information related to clinical trial experience but provided responses related to personal experiences with fCOI.

Almost all of the 732 investigators held primary university appointments. $67 \%$ had over five years of trial experience, and $64 \%$ had been the overall principal investigator for at least one trial (Table 2). More than $80 \%$ of investigators had participated in multi-site trials. Approximately half $(n=406)$ had been investigators on trials funded by both industry and non-industry sources.

\section{Preferred Practices}

700 investigators provided data about adherence to the practices designed to promote the objectivity of research in their non-industry ( $\mathrm{n}=646$ investigators) and industry $(n=460)$ funded trials (Table 3$)$.

Overall, in the trial preparation stage, 458 (65\%) investigators had a signed contract for one or more trials. Of these, 374 (82\%) investigators reported always having the contracts reviewed by the research ethics board (REB) or institution and $54(12 \%)$ reported no restrictive confidentiality clauses within the contract. 523 (75\%) reported always having their budgets reviewed by their REB or institution, and 274 (39\%) reported always having their trials registered (since 2005). For these 4 practices, full adherence was similar between industry and non-industry trials.

In the trial conduct stage, less than half of investigators reported full adherence to preferred practices in all of their trials with regards to data ownership (37\%); data access (38\%); control over study design (35\%); data 
Table 1 Survey questions related to preferred practices to promote the objectivity of research and their rationale

\begin{tabular}{ll}
\hline Practice & Rationale \\
\hline Signed contracts reviewed by institution [18] & $\begin{array}{l}\text { Reduce the risk of transparency } \\
\text { bias }\end{array}$ \\
\hline $\begin{array}{l}\text { Signed contracts do not have restrictive confidentiality clauses that prevent disclosure of trial information without } \\
\text { permission from the funder [17,18,29] }\end{array}$ & $\begin{array}{l}\text { Reduce the risk of publication } \\
\text { bias }\end{array}$ \\
\hline Budgetary reviewed by a REB or institutional official [3] & $\begin{array}{l}\text { Reduce the risk of transparency } \\
\text { bias }\end{array}$ \\
\hline Registration of a trial in a WHO approved registry since the requirement for trial registration in 2005 [10,30,31] & $\begin{array}{l}\text { Reduce the risk of publication } \\
\text { bias [32] }\end{array}$ \\
\hline Investigators rather than funder should have data ownership [17,18,33] & $\begin{array}{l}\text { Reduce the risk of reporting } \\
\text { bias }\end{array}$ \\
\hline Investigator should have access to data from all sites [11,12] & $\begin{array}{l}\text { Reduce the risk of reporting } \\
\text { bias }\end{array}$ \\
\hline Funder should not control final decisions regarding & $\begin{array}{l}\text { Reduce the risk of biased study } \\
\text { designs }\end{array}$ \\
\hline Study design [11,12] & $\begin{array}{l}\text { Reduce the risk of biased } \\
\text { analyses }\end{array}$ \\
\hline Data analysis [11,12] & $\begin{array}{l}\text { Reduce the risk of biased } \\
\text { interpretation }\end{array}$ \\
\hline Data interpretation [11,12] & $\begin{array}{l}\text { Reduce the risk of reporting } \\
\text { bias }\end{array}$ \\
\hline Funder should not control final decision on content of submitted manuscripts [11,12] & $\begin{array}{l}\text { Reduce the risk of reporting } \\
\text { bias }\end{array}$ \\
\hline
\end{tabular}

The survey questions related to preferred practices to promote the objectivity of research were based on the identified sources and the input of our research team.

analysis (39\%); and data interpretation (43\%). In the trial dissemination stage, 368 (53\%) investigators reported always having ultimate control over the contents of submitted manuscripts and 450 (64\%) reported an absence of ghost authorship in all their manuscripts. In addition to these reports of full adherence to preferred practice, other investigators reported following these preferred practices in some trials, but not all trials. Full adherence to preferred practices in the trial conduct and dissemination stages was generally higher for non-industry relative to industry funded trials.

We also stratified investigators according to whether they had experience in only a single funding environment or in both industry and non-industry funding environments and compared the frequency of preferred practices between industry and non-industry funded trials within these strata. We found no differences in the overall pattern of responses in either stratum. These results are not reported here but are available in Additional file 2.

\section{Personal Experience with $\mathrm{fCOI}$}

Overall, 269 (37\%) investigators reported having personally experienced or witnessed a situation involving fCOI (Table 4). These experiences were personal $(n=33)$, witnessed in a colleague $(n=184)$, or both $(n=52)$. Of 85 investigators who personally experienced a fCOI situation, the most frequent theme was related to recruitment (33\%). Another theme involved study conduct (24\%). 61 (72\%) indicated that these fCOI experiences involved industry-funded trials.

Of 236 investigators who reported witnessing a fCOI situation in a colleague's research, the most frequent theme related to personal financial incentives (24\%) (Table 4). 180 (76\%) of respondents indicated that the situations they witnessed were in relation to industryfunded trials.

\section{Discussion}

To our knowledge, our study is the first to obtain information directly from investigators about practices related to fCOI that may introduce bias into a trial at the preparation, conduct, and dissemination stages. Previous studies have largely relied on information obtained from indirect sources. For example, information on restrictive confidentiality clauses has come from surveys of medical school research administrators [17] while information on investigator participation in trial design, data access, and publications has come from surveys of medical schools officials [18]. Court documents have been the source of information for much of what we know about the practice of ghost authorship [19-23]

Our findings suggest that full adherence to preferred practice was highest when these practices are required and enforced by an external agent. Specifically, three 
Table 2 Investigator characteristics and clinical trial experience

\begin{tabular}{|c|c|}
\hline Characteristics & $\begin{array}{c}\text { Respondents }(\mathrm{N}=732) \\
\mathrm{n}(\%)\end{array}$ \\
\hline \multicolumn{2}{|l|}{ Primary appointment } \\
\hline University or academic teaching hospital & 684(93) \\
\hline Non-academic community-based hospital & $27(4)$ \\
\hline Other (e.g. private practice, cancer centre, pharmaceutical) & 21(3) \\
\hline \multicolumn{2}{|l|}{ Type of clinical trial } \\
\hline Non-industry trials only & $240(33)$ \\
\hline Industry trials only & $54(7)$ \\
\hline Both non-industry and industry trials & $406(55)$ \\
\hline None & 28(4) \\
\hline Did not answer & $4(1)$ \\
\hline \multicolumn{2}{|l|}{ Number of years of experience in clinical trials } \\
\hline$\leq 5$ & 192(26) \\
\hline$>5$ & $489(67)$ \\
\hline Not applicable & 28(4) \\
\hline Did not answer & 23(3) \\
\hline \multicolumn{2}{|l|}{ Most senior role in clinical trial } \\
\hline Principal investigator for entire trial -(trial PI) & $466(64)$ \\
\hline Principal investigator for site, No overall PI experience- (site PI) & $177(24)$ \\
\hline Other (No PI or site-PI experience) & $56(8)$ \\
\hline Did not answer & $33(5)$ \\
\hline \multicolumn{2}{|l|}{ Intervention(s) studied * } \\
\hline Drug therapy & $552(75)$ \\
\hline Device/equipment & $217(30)$ \\
\hline Diagnostic tests & $174(24)$ \\
\hline Surgery/procedure & $151(21)$ \\
\hline Education/counselling & 139(19) \\
\hline Management policy (e.g. specific thresholds for transfusion) & $89(12)$ \\
\hline Complementary and alternative medicine & $78(11)$ \\
\hline Psychotherapy & $37(5)$ \\
\hline Other (e.g. exercise, nutrition, radiation) & 113(15) \\
\hline \multicolumn{2}{|l|}{ Trial sites } \\
\hline Single & $94(13)$ \\
\hline Multiple & 252(34) \\
\hline Both (single and multiple) & $353(48)$ \\
\hline Did not answer & $33(5)$ \\
\hline \multicolumn{2}{|l|}{ Conflict of interest exposure } \\
\hline Any & 269(37) \\
\hline Personal only & $33(5)$ \\
\hline Witness of colleague & $184(25)$ \\
\hline Both personal and witness of colleague & $52(7)$ \\
\hline None & $402(55)$ \\
\hline Did not answer & $61(8)$ \\
\hline
\end{tabular}

Note:

* The sum of response options is greater than $100 \%$ because survey respondents may have investigated more than one intervention type in different trials.

quarters of investigators reported that all of their contracts and budgets were reviewed by an REB or an institutional official. Further, these practices were equally likely to occur in industry and non-industry funded trials. The high rate of compliance may reflect the requirement of institutions to review contracts and vigilance that ethics board members apply when they review studies [24]. Adherence to trial registration was also similar for industry and non-industry trials after 2005 (when registration became a precondition for publication in an 
Table 3 Adherence to the 11 preferred practices stratified by trial stage and funding

\begin{tabular}{|c|c|c|c|c|}
\hline \multirow[t]{4}{*}{ Practices } & \multicolumn{4}{|r|}{ Trial Funding } \\
\hline & Overall & $\begin{array}{c}\text { Non- } \\
\text { industry }\end{array}$ & Industry & $\begin{array}{c}\text { Adherence to preferred practice (Non-industry } \\
\text { vs. Industry) }\end{array}$ \\
\hline & $\begin{array}{l}(\mathrm{N}= \\
700)\end{array}$ & $\begin{array}{c}(\mathrm{N}=646) \\
*\end{array}$ & $\begin{array}{l}(\mathrm{N}= \\
460)^{\dagger}\end{array}$ & \\
\hline & $\mathrm{n}(\%)$ & $n(\%)$ & $\mathrm{n}(\%)$ & \\
\hline \multicolumn{5}{|c|}{ Trial Preparation Stage } \\
\hline \multicolumn{5}{|c|}{ Signed contracts reviewed by institution ${ }^{\neq}$} \\
\hline Signed contracts & 458 & 262 & 376 & \\
\hline No trials & 13(3) & $10(4)$ & 10(3) & \\
\hline Some trials & 39(9) & $21(8)$ & $18(5)$ & \\
\hline All trials ${ }^{\S}$ & $374(82)$ & $191(73)$ & 330(88) & Similar \\
\hline Not sure & $22(5)$ & $32(12)$ & $12(3)$ & \\
\hline Did not answer & $10(2)$ & $8(3)$ & $6(2)$ & \\
\hline \multicolumn{5}{|c|}{$\begin{array}{l}\text { Signed contracts have restrictive confidentiality } \\
\text { clauses } \neq\end{array}$} \\
\hline Signed contracts & 458 & 262 & 376 & \\
\hline No trials ${ }^{\S}$ & $54(12)$ & $48(18)$ & $28(7)$ & Similar \\
\hline Some trials & $99(22)$ & $35(13)$ & $58(15)$ & \\
\hline All trials & $201(44)$ & $77(29)$ & $212(56)$ & \\
\hline Not sure & $94(21)$ & $94(36)$ & $72(19)$ & \\
\hline Did not answer & $10(2)$ & $8(3)$ & $6(2)$ & \\
\hline \multicolumn{5}{|c|}{$\begin{array}{l}\text { Budgetary reviewed by a research ethics board or } \\
\text { institution official }\end{array}$} \\
\hline No trials & $39(6)$ & $49(8)$ & $22(5)$ & \\
\hline Some trials & $92(13)$ & $56(9)$ & 28(6) & \\
\hline All trials ${ }^{\S}$ & $523(75)$ & $487(75)$ & $386(84)$ & Similar \\
\hline Not sure & 28(4) & $38(6)$ & 18(4) & \\
\hline Did not answer & $18(3)$ & $16(2)$ & $6(1)$ & \\
\hline \multicolumn{5}{|c|}{ Trials registered in trial registry since 2005} \\
\hline No trials & $50(7)$ & $56(9)$ & $36(8)$ & \\
\hline Some trials & $221(32)$ & $173(27)$ & $69(15)$ & \\
\hline All trials $\S$ & 274(39) & 254(39) & $141(31)$ & Similar \\
\hline Not sure & 140(20) & $138(21)$ & 193(42) & \\
\hline Did not answer & 15(2) & $25(4)$ & $21(5)$ & \\
\hline \multicolumn{5}{|c|}{ Trial Conduct Stage } \\
\hline \multicolumn{5}{|l|}{ Funder owns study data } \\
\hline No trials ${ }^{\S}$ & 258(37) & $394(61)$ & $52(11)$ & Higher in non-industry \\
\hline Some trials & $221(32)$ & $42(7)$ & $114(25)$ & \\
\hline All trials & $107(15)$ & $68(11)$ & $172(37)$ & \\
\hline Not sure & $87(12)$ & 119(18) & $114(25)$ & \\
\hline Did not answer & $27(4)$ & 23(3) & $8(2)$ & \\
\hline \multicolumn{5}{|c|}{ Investigator has access to data from all sites } \\
\hline No trials & $80(11)$ & $69(11)$ & $61(13)$ & \\
\hline Some trials & $191(27)$ & $94(15)$ & $108(23)$ & \\
\hline All trials ${ }^{\S}$ & 265(38) & $306(47)$ & $99(22)$ & Higher in non-industry \\
\hline Not sure & 132(19) & $147(23)$ & $181(39)$ & \\
\hline Did not answer & $32(5)$ & $30(5)$ & $11(2)$ & \\
\hline
\end{tabular}

Funder controls final decisions regarding:

Study design

\begin{tabular}{|c|c|c|}
\hline No trials $\S$ & $247(35)$ & $366(57)$ \\
\hline Some trials & $228(33)$ & $46(7)$ \\
\hline
\end{tabular}


Table 3 Adherence to the 11 preferred practices stratified by trial stage and funding (Continued)

\begin{tabular}{|c|c|c|c|c|}
\hline All trials & $141(20)$ & 118(18) & 179(39) & \\
\hline Not sure & 63(9) & $98(15)$ & $84(18)$ & \\
\hline Did not answer & $21(3)$ & 18(3) & $7(2)$ & \\
\hline \multicolumn{5}{|l|}{ Data analysis } \\
\hline No trials $\S$ & 276(39) & $397(61)$ & $92(20)$ & Higher in non-industry \\
\hline Some trials & $222(32)$ & $37(6)$ & $114(25)$ & \\
\hline All trials & $120(17)$ & 109(17) & $155(34)$ & \\
\hline Not sure & $61(9)$ & $85(13)$ & $92(20)$ & \\
\hline Did not answer & 21(3) & 18(3) & $7(2)$ & \\
\hline \multicolumn{5}{|l|}{ Data interpretation } \\
\hline No trials ${ }^{\S}$ & $300(43)$ & $404(63)$ & $103(22)$ & Higher in non-industry \\
\hline Some trials & 207(30) & $36(6)$ & $111(24)$ & \\
\hline All trials & 106(15) & 106(16) & $126(27)$ & \\
\hline Not sure & $66(9)$ & $82(13)$ & $113(25)$ & \\
\hline Did not answer & $21(3)$ & 18(3) & $7(2)$ & \\
\hline \multicolumn{5}{|c|}{ Trial Dissemination Stage } \\
\hline \multicolumn{5}{|c|}{$\begin{array}{l}\text { Funder controls final decision on content of submitted } \\
\text { manuscripts }\end{array}$} \\
\hline No trials ${ }^{\S}$ & $368(53)$ & $445(69)$ & $124(27)$ & Higher in non-industry \\
\hline Some trials & $168(24)$ & $37(6)$ & $100(22)$ & \\
\hline All trials & $49(7)$ & $41(6)$ & $70(15)$ & \\
\hline Not sure & $88(13)$ & 100(15) & $157(34)$ & \\
\hline Did not answer & $27(4)$ & $23(4)$ & $9(2)$ & \\
\hline \multicolumn{5}{|c|}{ Completed manuscripts has ghost authorship } \\
\hline No trials ${ }^{\S}$ & $450(64)$ & $478(74)$ & $147(32)$ & Higher in non-industry \\
\hline Some trials & $100(14)$ & $35(5)$ & $75(16)$ & \\
\hline All trials & $5(1)$ & $4(1)$ & $8(2)$ & \\
\hline Not sure & $117(17)$ & 104(16) & 220(48) & \\
\hline Did not answer & $28(4)$ & 25(4) & $10(2)$ & \\
\hline
\end{tabular}

Notes:

* 646 investigators included 406 who had experience in both industry funding and non-industry funding trials and 240 who only had experience in non-industry funding trials. We defined non-industry funding as support from a government agency, hospital, university, or other non-profit source (e.g., a federal granting organization) and industry funding as support from a private for-profit corporation (e.g., pharmaceutical company).

+460 investigators included 406 who had experience in both industry funding and non-industry funding trials and 54 who only had experience in industry funding trials.

₹ Question was related to 458 investigators who had signed contracts.

$\S$ Rows indicated the proportion of investigators that reported full adherence to the specific preferred trial practice in all of their trials experience.

ICMJE journal [13]). Registration has been a legal requirement for all trials of interventions receiving regulatory approval in the United States since 2007 [10] and has been included in the World Medical Association Declaration of Helsinki since 2008 [25].

We found that adherence was lowest for preferred practices outlined by ICMJE regarding trial conduct and dissemination. There are a number of possible explanations for this result. First, these practices are recommended but not required by all medical journals. Second, the ICMJE recommendations generally target disclosure of information at the publication stage of the trial. Guidance introduced earlier in the process would alert investigators to preferred practices and encourage their incorporation into the study design. A fCOI
Checklist [26] aimed at prospectively identifying investigator fCOI in trials has been recently developed. To facilitate the conduct of preferred practices throughout the course of a clinical trial, this fCOI Checklist is intended to be initiated during the trial preparation stage and continues through to the trial's result dissemination stage [26].

Our data are consistent with previous evidence that a substantial proportion of trials have ghost authorship $[19,21,22]$. Less than a third of surveyed individuals indicated that ghost authorship was absent in all of their industry sponsored trials experience compared to more than two thirds for non-industry trials. A coordinated oversight strategy has been proposed to address this problem [19]. Increased awareness of this issue is 
Table 4 Thematic description of personal conflicts of interest situations

\begin{tabular}{|c|c|c|c|c|}
\hline \multirow{2}{*}{$\begin{array}{l}\text { Financial Conflict of } \\
\text { Interest }\end{array}$} & \multicolumn{2}{|r|}{ Experienced by Investigators } & \multicolumn{2}{|r|}{ Witnessed in Colleagues Research } \\
\hline & $\begin{array}{l}\text { Number } \\
(\%) \\
(\mathrm{N}=85)\end{array}$ & Examples from Free Text Comments & $\begin{array}{c}\text { Number } \\
(\%) \\
(\mathrm{N}=236)\end{array}$ & Examples from Free Text Comments \\
\hline Recruitment & $28(33)$ & - Pressure to recruit patients & $31(13)$ & $\begin{array}{l}\text { - Investigators receive direct benefit from enrolling } \\
\text { patients }\end{array}$ \\
\hline Study conduct & $20(24)$ & - Being asked to have a paper ghost-written & $37(16)$ & - Review focusing on trials with positive result \\
\hline $\begin{array}{l}\text { Personal financial } \\
\text { incentives }\end{array}$ & $9(11)$ & $\begin{array}{l}\text { - Possible financial gain by success of a drug/ } \\
\text { study }\end{array}$ & $56(24)$ & $\begin{array}{l}\text { - Equity holding in a company whose product is } \\
\text { being investigated }\end{array}$ \\
\hline Conflicting roles & $6(7)$ & $\begin{array}{l}\text { - Invented and patented devices and involved } \\
\text { in their study }\end{array}$ & $19(8)$ & $\begin{array}{l}\text { - Being the site principal investigator and the } \\
\text { patient's physician }\end{array}$ \\
\hline
\end{tabular}

important so that investigators understand the potential bias introduced by ghost authors.

Our findings are robust given that our original survey was worded so that investigators responded without explicit knowledge of the preferred behaviour. Additionally, identical questions were used to capture industry and non-industry funded trial experience. Our large number of respondents and reasonable response rate indicates the willingness of investigators to discuss potentially sensitive issues concerning their experiences. Our findings also describe the experiences of individual investigators. More than a third reported having personally experienced or witnessed a situation of potential fCOI, mostly in industry-funded trials. One of the most frequently described situations related to recruitment pressures. Our study indicates the need to explore this issue further.

\section{Limitations}

First, our sample of Canadian investigators may not reflect the perspectives of investigators globally. Increasingly, clinical research sites are moving to areas such as Eastern Europe and Latin America that may have less experience with clinical trials [27]. Second, our sample included only registered clinical trials. Since, registration has been a precondition for publication in an ICMJE journal since 2005 [13] the trials included in our sample may have been of higher quality than trials that were not registered. Some of the trials included in our sample predate the mandatory registration period. Third, response bias is a concern, particularly when addressing potentially sensitive issues involving fCOI. Our guarantee of anonymity, and user-friendly questions helped to encourage disclosure of useful information. The response rate to our email survey was $76 \%$ with $66 \%$ useable responses. We have no information from non-responders and therefore are unable to describe these individuals. Further, our main study outcome was full adherence to preferred practice in all of their trials experiences within 5-years of our survey. We recognize that other surveyed investigators followed the preferred practices in some but not all trials. Finally, we surveyed investigators about their trial experience prior to 2007. Since we aimed to capture practices across all stages of clinical trial conduct and study result dissemination (average 4 to 8 years from inception to completion [28]), we needed to allow sufficient time for publication. Our results may not fully reflect current practices but they provide a baseline from which future studies can build.

\section{Conclusions}

Full adherence to practices designed to promote the objectivity of research varied across trial stages and was low overall, particularly for industry funded trials. Adherence to preferred practices was highest when they were required by an external agent. Guidance introduced early in the trial process could alert investigators to preferred practices and encourage their incorporation into the study design.

\section{Funding Support}

This project was funded by Canadian Institutes of Health Research (CIHR) Grant entitled Evaluation of the Integrity of Clinical Research in Canada EIC - 77338. The funding organizations did not participate in the design or conduct of the study, in the collection, analysis, or interpretation of the data, or in the preparation, review, or approval of the manuscript. Dr. Rochon had full access to all of the data in the study and takes responsibility for the integrity of the data and the accuracy of the data analysis.

\section{Additional material}

Additional file 1: Survey questions.

Additional file 2: Adherence to the 11 preferred practices stratified by trial stage and funding.

\section{Acknowledgements}

We would like to thank Lori Lyons for her editorial comments, and Peter Anderson for technical assistance. This manuscript was presented at the 
Sixth International Congress on Peer Review and Biomedical Publication in Vancouver, Canada in September 2009

\section{Author details}

'Women's College Research Institute at Women's College Hospital, Toronto, Canada. ${ }^{2}$ Department of Physiology University of Toronto, Toronto, Canada. ${ }^{3}$ Dalla Lana School of Public Health, University of Toronto, Toronto, Canada. ${ }^{4}$ School of Health Policy and Management, York University, Toronto, Canada. ${ }^{5}$ Emergency Department, University Health Network, Toronto, Canada. ${ }^{6}$ Department of Family and Community Medicine, University of Toronto, Toronto, Canada. ${ }^{7}$ Clinical Epidemiology Methods Centre, Ottawa Health Research Institute; Department of Epidemiology and Community Medicine, Faculty of Medicine, University of Ottawa. Ottawa, Canada. ${ }^{8}$ Toronto Rehabilitation Institute, Toronto, Canada. ${ }^{9}$ Joint Centre for Bioethics, University of Toronto, Toronto, Canada. ${ }^{10}$ Ontario Medical Association, Toronto, Canada. ${ }^{11}$ Division of Emergency Medicine, University of Toronto, Toronto, Canada. ${ }^{12}$ Department of Psychiatry, University of Toronto, Toronto, Canada.

\section{Authors' contributions}

PAR, JH, JL, LEF, DM, MVL, JG, JM, DS, NT, AWC conceived the project; PAR, $J H, J L, L E F, D M, J G, J M, D S, N T$, AWC obtained the funding; PAR, MS, JH, JL, LEF, DM, MVL, JG, JM, NT, AWC participated in the design of the survey; MS, SRK were research assistants on the study and were involved in data collection; PAR, MS, JH, JL, LEF, DM, WW, SRK, MVL, AG, JM, DLS, NT, AWC participated in analyzing the research; PAR, MS, JH, JL, LEF, DM, WW, SRK, $M V L, A G, J G, J M, D L S, N T$, AWC helped to draft the manuscript, and approved the final manuscript

PAR is the study guarantor.

\section{Competing interests}

Joel Lexchin was retained by a law firm representing Apotex to provide expert testimony about the effects of promotion on the sales of medications. He has also been retained as an expert witness by the Canadian federal government in its defense of a law suit launched challenging the ban on direct-to-consumer advertising of prescription drugs in Canada. No conflicts reported for rest of the authors.

Received: 1 April 2010 Accepted: 12 January 2011

Published: 12 January 2011

\section{References}

1. Sim I, Detmer DE: Beyond trial registration: a global trial bank for clinical trial reporting. PLoS Med 2005, 2(11):e365

2. Chan AW, Altman DG: Epidemiology and reporting of randomised trials published in PubMed journals. Lancet 2005, 365(9465):1159-62.

3. CIHR, Tri-council policy statement: ethical conduct for research involving humans, 1998 (with 2000, 2002, 2005 amendments). Canadian Institutes of Health Research, Natural Sciences and Engineering Research Council of Canada, Social Sciences and Humanities Research Council of Canada; 2005.

4. 42 CFR 50 (f): Code of Federal Regulations. 2000 [http://grants.nih.gov/ grants/compliance/42_CFR_50_Subpart_F.htm].

5. 21 CFR 54: Financial Disclosure by Clinical Investigators. Code of Federal Regulations. [http://www.accessdata.fda.gov/scripts/cdrh/cfdocs/cfcfr/ CFRSearch.cfm?CFRPart=54].

6. Department of Health and Human Services: Financial Relationships and Interests in Research Involving Human Subjects: Guidance for Human Subject Protection. 2004 [http://www.hhs.gov/ohrp/policy/fguid.pdf].

7. Department of Health and Human Services: Guidance on Engagement of Institutions in Human Subjects Research. 2008 [http://www.hhs.gov/ohrp/ policy/engage08.html].

8. AAMC, Protecting Subjects, Preserving Trust, Promoting Progress II: Principles and Recommendations for Oversight of an Institution's Financial Interests in Human Subjects Research: Task Force on Financial Conflicts of Interest in Clinical Research. AAMC; 2002.

9. AAMC, Protecting Patients, Preserving Integrity, Advancing Health: Accelerating the Implementation of COI Policies in Human Subjects Research. A Report of the AAMC-AAU Advisory Committee on Financial Conflicts of Interest in Human Subjects Research. AAMC: Washington, D. C.; 2008, 87 .
10. U.S. Public Law 110-85 (Food and Drug Administration Amendments Act of 2007 or FDAAA), Title VIII, Section 801. 2007.

11. International Committee of Medical Journal Editors: Uniform Requirements for Manuscripts Submitted to Biomedical Journals: Writing and Editing for Biomedical Publication. 2004 [http://www.icmje.org/2004_urm.pdf].

12. International Committee of Medical Journal Editors: Uniform Requirements for Manuscripts Submitted to Biomedical Journals: Writing and Editing for Biomedical Publication. 2008 [http://www.icmje.org/2008_urm.pdf].

13. De Angelis CD, Drazen JM, Frizelle FA, Haug C, Hoey J, Horton R, Kotzin S, Laine C, Marusic A, Overbeke AJ, Schroeder TV, Sox HC, Van Der Weyden MB: Is this clinical trial fully registered?-A statement from the International Committee of Medical Journal Editors. N Engl J Med 2005, 352(23):2436-8.

14. metaRegister of Controlled Trials (mRCT) - active registers. [http://www. controlled-trials.com/mrct].

15. Policy Statements: Authorship. 2007 [http://www.wame.org/resources/ policies\#authorship].

16. Schulz KF, Moher D, Altman DG, CONSORT Group: CONSORT 2010 Statement: Updated guidelines for reporting parallel-group randomized trials. Trials 2010, 11(1):32.

17. Mello MM, Clarridge BR, Studdert DM: Academic Medical Centers' Standards for Clinical-Trial Agreements with Industry. N Engl J Med 2005, 352:2202-10.

18. Schulman KA, Seils DM, Timbie JW, Sugarman J, Dame LA, Weinfurt KP, Mark DB, Califf RM: A national survey of provisions in clinical-trial agreements between medical schools and industry sponsors. N Engl J Med 2002, 347(17):1335-41.

19. Ross JS, Hill KP, Egilman DS, Krumholz HM: Guest authorship and ghostwriting in publications related to rofecoxib: a case study of industry documents from rofecoxib litigation. JAMA 2008, 299(15):1800-12.

20. Steinman MA, Bero LA, Chren MM, Landefeld CS: Narrative review: the promotion of gabapentin: an analysis of internal industry documents. Annals of Internal Medicine 2006, 145(4):284-93.

21. Gotzsche PC, Hrobjartsson A, Johansen HK, Haahr MT, Altman DG, Chan AW: Constraints on publication rights in industry-initiated clinical trials. JAMA 2006, 295(14):1645-6.

22. Gotzsche PC, Hrobjartsson A, Johansen HK, Haahr MT, Altman DG Chan AW: Ghost authorship in industry-initiated randomised trials. PLOS Medicine/Public Library of Science 2007, 4(1):e19.

23. Flanagin A, Carey LA, Fontanarosa PB, Phillips SG, Pace BP, Lundberg GD, Rennie D: Prevalence of articles with honorary authors and ghost authors in peer-reviewed medical journals. JAMA 1998, 280(3):222-4.

24. Weissman JS, Koski G, Vogeli C, Thiessen C, Campbell EG: Opinions of IRB Members and Chairs Regarding Investigators' Relationships with Industry. J Empir Res Hum Res Ethics 2008, 3(1):3-13.

25. Declaration of Helsinki. 2008 [http://www.wma.net/en/30publications/ 10policies/b3/index.html].

26. Rochon PA, Hoey J, Chan AW, Ferris LE, Lexchin J, Kalkar SR, Sekeres M, Wu W, Van Laethem M, Gruneir A, Maskalyk J, Streiner DL, Gold J, Taback N, Moher D: Financial Conflicts of Interest Checklist 2010 for clinical research studies. Open Medicine 2010, 4(1):69-91.

27. Rehnquist J: The Globalization of Clinical Trials: A Growing Challenge in Protecting Human Subjects. Department of Health and Human Services, Office of Inspector General Report; 2001 [http://oig.hhs.gov/oei/reports/oei01-00-00190.pdf].

28. Hopewell S, Clarke M, Stewart L, Tierney J: Time to publication for results of clinical trials. Cochrane Database Syst Rev 2007, 2:MR000011.

29. Naylor CD: Early Toronto experience with new standards for industrysponsored clinical research: a progress report. CMAJ 2002, 166:453-6.

30. International Clinical Trials Registry Platform (ICTRP):[http://www.who.int/ ictrp/network/en/].

31. Laine $C$, Horton $R$, DeAngelis CD, Drazen JM, Frizelle FA, Godlee F, Haug C, Hebert PC, Kotzin S, Marusic A, Sahni P, Schroeder TV, Sox HC, Van der Weyden MB, Verheugt FW: Clinical trial registration-looking back and moving ahead. New England Journal of Medicine 2007, 356(26):2734-6.

32. Moher D, Bernstein A: Registering ClHR-funded randomized controlled trials: a global public good. CMAJ 2004, 171(7):750-1.

33. Access to and Retention of Research Data: Rights and Responsibilities. 2006 [http://206.151.87.67/docs/CompleteDRBooklet.htm]. 
34. Ghost Writing Initiated by Commercial Companies. Policy Statements: Prepared by the WAME Editorial Policy Committee. [http://www.wame. org/resources/policies\#ghost].

doi:10.1186/1745-6215-12-9

Cite this article as: Rochon et al:: Investigator experiences with financial conflicts of interest in clinical trials. Trials 2011 12:9.

Submit your next manuscript to BioMed Central and take full advantage of:

- Convenient online submission

- Thorough peer review

- No space constraints or color figure charges

- Immediate publication on acceptance

- Inclusion in PubMed, CAS, Scopus and Google Scholar

- Research which is freely available for redistribution 